\title{
A EDUCAÇÃO COMO INSTRUMENTO PARA O DESENVOLVIMENTO SUSTENTÁVEL E REAFIRMAÇÃO DOS DIREITOS FUNDAMENTAIS
}

\author{
Luciana Andréa França Silva ${ }^{1}$ \\ Wanderson Dias Fernandes ${ }^{2}$
}

RESUMO: A presente pesquisa busca analisar a educação ambiental como forma de construção de uma consciência ambiental reconhecendo a necessidade de mudança de atitudes rumo a um desenvolvimento sustentável como forma de garantia de efetividade do direito fundamental ao meio ambiente ecologicamente equilibrado. O objetivo da pesquisa é apresentar de forma crítica a necessidade de investimento na educação ambiental como forma de se atingir a plena sustentabilidade.

Palavras-chave: Sustentabilidade; Desenvolvimento Sustentável; Educação; Direito Fundamental ao Meio Ambiente Ecologicamente Equilibrado.

\section{THE EDUCATION AS INSTRUMENT TO SUSTAINABLE DEVELOPMENT AND REAFFIRMING FUNDAMENTAL RIGHTS}

\begin{abstract}
The present research seeks to analyze environmental education as a way of building an environmental awareness, recognizing the need to change attitudes towards sustainable development as a way of guaranteeing the effectiveness of the fundamental right of the ecologically balanced environment. The objective of the research is to critically present the need for investment in environmental education as a way to achieve full sustainability.
\end{abstract}

Keywords: Sustainability; Sustainable development; Education; Fundamental Right to the Environment Ecologically Balanced.

\footnotetext{
${ }^{1}$ Mestranda no Programa de pós-graduação Stricto Sensu da Universidade de Itaúna. Bacharel em Direito pela Universidade de Itaúna. Especialista em Direito Civil pela Universidade Anhanguera Uniderp. Advogada. Email: lucianaandrea@bol.com.br.

${ }^{2}$ Mestrando no Programa de pós-graduação Stricto Sensu da Universidade de Itaúna. Bacharel em Direito pela Universidade de Itaúna. Especialista em Psicopedagogia e Interdisciplinaridade pela Universidade de Itaúna. Docente na Faculdade Pitágoras em Divinópolis/MG. Defensor Público do Estado de Minas Gerais. Email: wander.df@uol.com.br.
} 


\section{INTRODUÇÃO}

Atualmente nos deparamos com diversos acontecimentos relacionados ao clima e o aparecimento de diversos problemas em áreas produtivas de nosso planeta aliado às mudanças climáticas além de convivermos com mudanças que culminam por causar diversas catástrofes ambientais.

Os problemas ocorridos nos últimos tempos ocorrem devido à influência da maneira na qual a humanidade escolheu para explorar os recursos naturais oferecidos pelo planeta, promovendo uma verdadeira pilhagem do meio ambiente ocasionando, com isso, uma resposta ambiental em forma de desastres de grandes proporções além da potencial diminuição dos atuais recursos.

A humanidade encontra-se em um dilema em que ou mudamos a maneira como usufruímos dos recursos naturais voltados a um desenvolvimento sustentável com vistas à preservação dos recursos naturais ou comprometer a sobrevivência desta e das futuras gerações, com a diminuição de recursos e comprometimento do equilíbrio do meio ambiente.

A mudança rumo ao desenvolvimento sustentável com o uso dos recursos naturais de forma consciente deve ser traçada por meio da implementação de programas capazes de mudar forma de consumo com a adoção de práticas voltadas à sustentabilidade com a diminuição de qualquer potencial impacto que a utilização do meio ambiente venha a alterar o ecossistema que nos circunda e mantém.

O presente estudo procura demonstrar a importância da aplicação de uma política que promova a educação ambiental principalmente voltada para o desenvolvimento sustentável e a sustentabilidade já nas escolas primárias como forma de criar nas novas gerações a consciência ambiental para facilitar a implementação de políticas que visem à utilização sustentável dos recursos naturais.

Reconhecendo muito mais que a simples causa do meio ambiente, é necessária uma análise da educação ambiental voltada para a sustentabilidade analisando um amplo espectro de fatores que leva em consideração que a mudança de postura se faz necessária quando se analisa os indivíduos afetados pelas atividades reconhecendo que somente com a conscientização ambiental teremos garantido um meio ambiente equilibrado, direito 
fundamental reconhecido na Constituição Federal de $1.988^{3}$ para a presente e as futuras gerações.

Reconhecidamente a mudança de pensamento está relacionada a uma educação sustentável, uma vez que a sustentabilidade só será alcançada por meio de políticas visando a educação e a conscientização, tanto da atual quanto das futuras gerações.

Analisando e conceituando o Desenvolvimento sustentável e a sustentabilidade por meio de um breve estudo, o presente trabalho fará uma análise sobre as três dimensões da sustentabilidade detectando a importância da educação sutentável como forma de mudança na conscientização ambiental e de que forma a educação poderá ser utilizada como instrumento para alcançar um modelo sustentável para a humanidade.

Portanto, o objetivo da pesquisa é apresentar e verificar de forma crítica como a educação ambiental poderá ser utilizada para mudar rumo a um desenvolvimento sustentável garantindo o direito fundamental ao meio ambiente equilibrado.

A metodologia utilizada foi a revisão bibliográfica, baseada em fontes primárias e secundárias, utilizando-se o método dedutivo.

\section{O DESENVOLVIMENTO SUSTENTÁVEL E A SUSTENTABILIDADE}

Para uma melhor análise em nosso estudo necessário faz-se conhecer o Desenvolvimento Sustentável como um conceito relacionado a um modelo de desenvolvimento global onde são incorporados aspectos que se ligam a uma sociedade que fomenta cada dia mais o consumo em massa sem ignorar a necessidade da preservação da natureza.

O conceito de desenvolvimento sustentável foi utilizado pela primeira vez em 1.987, no Relatório Brundtland, elaborado pela Comissão Mundial sobre Meio Ambiente e Desenvolvimento que foi criado em 1983 pela Assembleia das Nações Unidas.

A definição utilizada para o desenvolvimento sustentável neste relatório é:

O desenvolvimento que procura satisfazer as necessidades da geração atual, sem comprometer a capacidade das gerações futuras de satisfazerem as suas próprias necessidades, significa possibilitar que as pessoas, agora e no futuro, atinjam um nível satisfatório de desenvolvimento social e econômico e de realização humana e cultural, fazendo, ao mesmo tempo, um uso

\footnotetext{
${ }^{3}$ Art. 225. Todos têm direito ao meio ambiente ecologicamente equilibrado, bem de uso comum do povo e essencial à sadia qualidade de vida, impondo-se ao poder público e à coletividade o dever de defendê-lo e preserválo para as presentes e futuras gerações.
} 
razoável dos recursos da terra e preservando as espécies e os habitats naturais. ${ }^{4}$

Ao lado da conceituação relacionada ao Desenvolvimento Sustentável, surge o termo Sustentabilidade como uma definição para ações e atividades humanas visando suprir as necessidades atuais dos seres humanos, com a preocupação de não se comprometer o futuro das próximas gerações. Em outras palavras, a sustentabilidade está relacionada diretamente com o desenvolvimento econômico e material sem agredir o meio ambiente, com utilização dos recursos naturais de forma racional para que eles se mantenham no futuro. Seguindo estes parâmetros, a humanidade pode garantir o desenvolvimento sustentável.

Recentemente, em 25 de setembro de 2015, a Assembléia Geral da ONU editou Agenda 2.030 para o Desenvolvimento Sustentável (ONU, 2015) com o objetivo de redirecionar a humanidade para um caminho sustentável. A agenda 2.030 foi desenvolvida após a edição da Agenda do Desenvolvimento Sustentável (Rio+20) no Rio de Janeiro, em um processo de três anos com a participação dos Estados-Membros da ONU e a realização de inquéritos nacionais que envolveram milhões de pessoas e milhares de atores de todo o mundo.

A Agenda 2.030 aponta dezessete objetivos do Desenvolvimento Sustentável com vistas a uma transformação universal para combater os grandes desafios de desenvolvimento para a humanidade. O principal objetivo é assegurar uma vida sustentável, pacífica, próspera e eqüitativa no planeta para todos agora e no futuro.

As metas abrangem desafios globais que são cruciais para a sobrevivência da humanidade estabelecendo limites ambientais críticos para a utilização dos recursos naturais. Os objetivos reconhecem que a erradicação da pobreza deve ir de mãos dadas com estratégias que permitam o desenvolvimento econômico. Elas abordam uma série de questões sociais, incluindo a educação, a saúde, a proteção social das oportunidades de emprego, abordando simultaneamente as alterações proteção ambiental.

Os objetivos do Desenvolvimento Sustentável abordam questões que trazem barreiras ao desenvolvimento sustentável, como a desigualdade, os padrões de consumo insustentáveis e a degradação ambiental.

No entanto, para que os objetivos sejam atingidos, todos precisam fazer a sua parte: Governos, o setor privado, a sociedade civil e todos os Estados em todo o mundo. Espera-se

\footnotetext{
${ }^{4}$ Relatório Burtland. "Our Common Future”. Elaborado pela Comissão Mundial sobre Meio Ambiente e Desenvolvimento em 1.987.
} 
que os governos estabeleçam marcos, políticas nacionais e medidas para a implementação da Agenda de 2.030.

A característica fundamental do pensamento ligado ao desenvolvimento Sustentável é a sua universalidade e indivisibilidade uma vez que as metas são endereçadas a todos os países sem distinção para alinhar os seus próprios esforços com o objetivo de promover a prosperidade com a preocupação de se proteger simultaneamente o Desenvolvimento Sustentável.

\section{AS TRÊS DIMENSÕES DO DESENVOLVIMENTO SUSTENTÁVEL}

Para tratar das questões relacionadas à sustentabilidade é necessária uma maior integração das três dimensões do desenvolvimento sustentável: econômica, social e ambiental.

Esta integração das dimensões é perfeita para entender a sustentabilidade. As três dimensões estão relacionadas aos aspectos econômicos, ambientais e sociais, que devem interagir de uma forma integrativa para se alcançar o desenvolvimento sustentável pleno. Sem estas três dimensões a sustentabilidade não pode ser alcançada. Há, ainda, uma discussão sobre outras dimensões, como a questão cultural, tecnológica, social, ética, jurídico-política para complementar a sustentação da questão como um todo.

Não podemos afastar a ideia de que esses conceitos e dimensões podem e devem ser aplicados tanto no aspecto amplo de um país, um Estado ou o próprio planeta como em um microssistema como uma atividade empresarial, uma casa ou até mesmo um pequeno grupo que explore uma atividade agrária organizada como uma cooperativa.

No que tange à Dimensão Social podemos relacioná-la com o capital humano de uma sociedade como um todo. Neste contexto, como bem ensina o professor Juarez Freitas:

\footnotetext{
Dimensão social, no sentido de que não se admite o modelo do desenvolvimento excludente e iníquo. De nada serve cogitar da sobrevivência enfastiada de poucos, encarcerados no estilo oligárquico, relapso e indiferente, que nega a conexão de todos os seres vivos, a ligação de tudo e, desse modo, a natureza imaterial do desenvolvimento. (FREITAS, 2016, p.62)
}

Há, portanto, na dimensão social os direitos fundamentais sociais que devem ser tratados com vistas à eficiência e eficácia, sob pena de o modelo de governança (pública e privada) ser autofágico e, numa palavra, insustentável. (FREITAS, 2016, p.63).

O desenvolvimento deve se dar com vistas a garantir uma redução significativa das desigualdades sociais. Neste contexto, uma forma em que as desigualdades sejam reduzidas e 
que haja uma conscientização sobre a necessidade de uma sustentabilidade que se perpetue para as próximas gerações pode ser efetivada através da educação.

Com relação à Dimensão Ambiental do Desenvolvimento Sustentável podemos afirmar que a preocupação está alicerçada nas seguintes premissas: redução das emissões de carbono causadas pelo desmatamento, gestão florestal sustentável, modelos de produção e consumo sustentáveis, gestão de recursos hídricos, proteção do ambiente e conservação de ecossistemas, prevenção da perda de biodiversidade, poluição e gestão de resíduos e desperdícios, tecnologias eficiente em recurso, cooperação em pesquisa ambiental e governança internacional na área ambiental.

O que não faz o menor sentido é persistir na matriz comportamental da degradação e do poder neurótico sobre a natureza, não somente porque os recursos naturais são finitos, mas porque tal despautério faz milhões de vítimas pelo caminho. É altamente falacioso tentar escapar das responsabilidades pelos desequilíbrios ambientais, atribuindo exclusivamente a culpa à natureza, mecanismo clássico de fuga pusilânime. (FREITAS, 2016, p. 69)

Nesse aspecto, a sociedade deve repensar formas de amenizar os impactos do desenvolvimento e compensar o que, de alguma forma não for possível amenizar. Além disso, deve ser levada em conta a adequação da legislação ambiental e a vários princípios discutidos atualmente.

Por fim, ao tratarmos da Dimensão Econômica em que são analisados os temas ligados à produção, distribuição e consumo de bens e serviços levando-se em conta os outros dois aspectos, considerando a definição da atividade econômica, ou seja, conjunto de atividades desenvolvidas pelos homens visando à produção, distribuição e o consumo de bens e serviços necessários à sobrevivência e à qualidade de vida.

A Dimensão Econômica da sustentabilidade evoca, aqui, a pertinente ponderação, o adequado "trade-off" entre eficiência e equidade, isto é, o sopesamento fundamentado, em todos os empreendimentos (públicos e privados), dos benefícios e dos custos direitos e indiretos (externalidades). A economicidade, assim, não pode ser separada da medição das consequências, de longo prazo. Nessa perspectiva, o consumo e a produção precisam ser reestruturados completamente, numa alteração inescapável do estilo de vida. (FREITAS, 2016, p. 70).

É inegável, portanto, que a sustentabilidade gera uma nova economia, passando pela reformulação de categorias e comportamentos, privilegiando o planejamento a longo prazo, onde os incentivos estão ligados à eficiência norteada pela eficácia.

\section{A EDUCAÇÃO PARA O DESENVOLVIMENTO SUSTENTÁVEL E A EDUCAÇÃO}




\section{AMBIENTAL}

É na educação que se constrói nos indivíduos a consciência da necessidade de preservação do patrimônio ambiental, demonstrando que esta consciência começa com pequenas ações, e que estas é que efetivam o desenvolvimento sustentável macroeconômico.

A educação relacionada ao meio ambiente é contemporânea ao homem, uma vez que, para sua sobrevivência era necessário que os seres humanos conhecessem e soubessem se relacionar com o meio ambiente. E desde o início dos tempos, quando os seres humanos passaram a se relacionar com o meio ambiente fez-se necessário que o conhecimento deste fosse repassado a seus descendentes, havendo, portanto o início da educação ambiental.

A sociedade encontra-se em constante diálogo com a educação onde a escola se relaciona com a obrigação na formação de cidadãos consciente que saibam detectar os problemas da comunidade e do mundo, além de possuírem a capacidade da tomada de decisões na busca de algo melhor.

Reconhecer uma prática educacional voltada para a educação ambiental é o desafio rumo à redução dos problemas sociais, econômicos e ambientais que ocorre no planeta hoje em dia e, neste sentido, a para que se ensine uma verdadeira educação ambiental é necessária a introdução de conceitos de sustentabilidade em toda a formação escolar, iniciando-se desde a tenra idade na pré-escola aplicando-se inclusive até à formação universitária.

Não se pode negar que a fase da vida mais importante para o desenvolvimento da cidadania é a infância. E é nessa fase que devem ser introduzidos os conceitos de desenvolvimento sustentável e a conscientização de práticas voltadas à preservação do meio ambiente.

A prática educacional voltada para a sustentabilidade e para a formação de uma consciência ambiental deve estar voltadas para várias questões, como por exemplo: como usar os recursos naturais de forma responsável, qual é a importância da natureza na vida do homem, como devem ser separados os resíduos de casa, etc.

Com relação à educação ambiental é fundamental que seja aplicada na prática o que aprendido no ambiente escolar. Vivenciar o comportamento ecológico é importante com diversas propostas para incentivar projetos pedagógicos e atividades extracurriculares voltadas para a conscientização dos problemas que a natureza suporta e como resolvê-los, também como forma de chamar a atenção da sociedade para o ambiente escolar com o intuito de mobilização para um espírito solidário e comunitário no enfrentamento de soluções para minimizar o 
impacto da ação humana na degradação ambiental.

O Estado também deve implementar ações como resposta à Constituição Federal, que em seu art. $225 \S 1^{\circ}$ traz a imposição para o poder público de assegurar a efetividade do direito ao meio ambiente ecologicamente equilibrado deve direito com a incumbência de, entre outras, promover a educação ambiental em todos os níveis de ensino e a conscientização pública para a preservação do meio ambiente ${ }^{5}$.

O papel do poder público é essencial na aplicação de práticas educativas no ambiente escolar, seja por elaboração de leis, seja por previsão nas grades curriculares das escolas públicas como a iniciação de projetos de sustentabilidade voltados à educação.

A Constituição Federal reconhece a necessidade da participação do poder público em conjunto com a coletividade para uma real mudança nos problemas mundiais rumo ao desenvolvimento sustentável. Somente a educação ambiental tem a capacidade de formar cidadãos conscientes sobre as necessidades do meio ambiente criando perspectivas para um desenvolvimento sustentável tornando, no entanto, necessária a participação do governo, da sociedade e da escola na construção de uma consciência ambiental.

\section{A EDUCAÇÃO PARA O DESENVOLVIMENTO SUSTENTÁVEL - UM INSTRUMENTO FUNDAMENTAL PARA ATINGIR OS OBJETIVOS DA SUSTENTABILIDADE}

A educação tradicionalmente configura um dos valores de natureza social mais significativo relacionado à melhoria e à transformação da sociedade, sendo mais que uma

\footnotetext{
${ }^{5}$ Art. 225. (...)

$\S 1^{\circ}$ Para assegurar a efetividade desse direito, incumbe ao poder público:

I - preservar e restaurar os processos ecológicos essenciais e prover o manejo ecológico das espécies e ecossistemas;

II - preservar a diversidade e a integridade do patrimônio genético do País e fiscalizar as entidades dedicadas à pesquisa e manipulação de material genético;

III - definir, em todas as unidades da Federação, espaços territoriais e seus componentes a serem especialmente protegidos, sendo a alteração e a supressão permitidas somente através de lei, vedada qualquer utilização que comprometa a integridade dos atributos que justifiquem sua proteção;

IV - exigir, na forma da lei, para instalação de obra ou atividade potencialmente causadora de significativa degradação do meio ambiente, estudo prévio de impacto ambiental, a que se dará publicidade;

V - controlar a produção, a comercialização e o emprego de técnicas, métodos e substâncias que comportem risco para a vida, a qualidade de vida e o meio ambiente;

VI - promover a educação ambiental em todos os níveis de ensino e a conscientização pública para a preservação do meio ambiente;

VII - proteger a fauna e a flora, vedadas, na forma da lei, as práticas que coloquem em risco sua função ecológica, provoquem a extinção de espécies ou submetam os animais a crueldade.
} 
exigência ligada aos processos produtivos e de inserção profissional, correspondendo a valores da cidadania social e política.

Tendo em vista a relevância da educação e sua importância na construção da cidadania em prol do bem comum e de uma sociedade mais justa a Constituição Federal de 1.988 tem um importante papel na consolidação das noções que permeiam o seu acesso, incluindo no rol dos direitos fundamentais o direito à educação, amparado, também, por diversos diplomas internacionais ${ }^{6}$.

A educação tem o importante papel de formação integral do indivíduo que abrange a formação pessoal e profissional, preparando o homem para o convívio na sociedade com base em valores humanos que convergem para o respeito e consideração ao próximo e sua a formação técnica-profissional para a busca de condições dignas de trabalho e de sobrevivência.

De acordo com Irina Bokova, Diretora-Geral da UNESCO:

\begin{abstract}
“A fundamental change is needed in the way we think about education's role in global development, because it has a catalytic impact on the well-being of individuals and the future of our planet. ... Now, more than ever, education has a responsibility to be in gear with 21st century challenges and aspirations, and foster the right types of values and skills that will lead to sustainable and inclusive growth, and peaceful living together. “7
\end{abstract}

É, portanto, necessária uma mudança fundamental na forma de pensar a educação e seu papel no desenvolvimento global há grande um impacto catalítico no bem estar de todos e no futuro do nosso planeta. Agora, mais do que nunca, a educação tem a responsabilidade de se reorganizar com os desafios e as aspirações do século XXI, promovendo os tipos certos de valores e habilidades que conduzirá a um crescimento sustentável e inclusivo para uma convivência pacífica.

Segundo a UNESCO "A educação pode e deve contribuir para uma nova visão Desenvolvimento sustentável global". (UNESCO, 2015). Para que isso ocorra é necessária uma profunda transformação na maneira de como pensamos, e o mais importante, na maneira como utilizamos os recursos naturais.

A educação ambiental torna-se instrumento de aplicação do desenvolvimento

\footnotetext{
${ }^{6}$ Não são poucos os documentos de caráter internacional, assinados por países da Organização das Nações Unidas, que reconhecem e garantem esse acesso a educação. Alguns exemplos são o Pacto Internacional relativo aos Direitos Econômicos, Sociais e Culturais (1966), a Convenção sobre os Direitos da Criança (1989), a Declaração Mundial sobre Educação Para Todos (1990), a Declaração de Amsterdã (2004) e a Declaração de Jacarta (2005).

${ }^{7}$ Irina Bokova, Director-General of UNESCO in Education for Sustainable Development Goals: Learning Objectives, p. 7
} 
sustentável na medida em que conscientiza nossas crianças sobre a necessidade de preservação de um meio ambiente equilibrado em que os recursos são utilizados de maneira tal que possa ser também utilizado pelas futuras gerações.

Reconhecer o Desenvolvimento Sustentável exige uma profunda transformação na forma como pensamos e agimos. Para seguirmos rumo à sustentabilidade os indivíduos dever tomar decisões de mudança onde se exige o conhecimento, habilidades, valores e atitudes que os capacitam para o Desenvolvimento Sustentável.

A educação é, portanto, crucial, mas não qualquer tipo de educação. A educação que promove e incentiva o desenvolvimento econômico sozinho somente aumenta os padrões de consumo insustentável. A educação voltada para o Desenvolvimento Sustentável capacita as crianças para a tomada de decisões e ações ambientais com viabilidade econômica, integridade com a preocupação na construção de uma sociedade mais justa para as futuras gerações.

Segundo ABÍLIO (2008):

No desenvolvimento do processo educativo, voltado para a construção da cidadania e
a conscientização ambiental, deve-se traçar experiências de participação social que
propiciem a vivência de comportamentos individuais e coletivos, assim como
provocar o desenvolvimento de novas habilidades e competências no âmbito da
temática ambiental (ABÍLIO, 2008, p.354).

A educação para o Desenvolvimento Sustentável visa desenvolver competências nos indivíduos para que estes possam refletir sobre suas próprias ações no campo cultural, social e econômico. Deve-se também desenvolver uma consciência para a ação em situações complexas de forma sustentável.

A necessidade de uma nova conscientização deve ser entendida como parte integrante de toda a educação ao longo da vida, por todas as instituições educacionais, desde a educação pré-escolar até o ensino superior, seja na educação formal como na informal considerando a responsabilidade de todos para tratar de questões de desenvolvimento sustentável.

A educação ambiental deve estar voltada para o estudo de problemáticas ambientais relacionadas a todos os componentes biofísicos e sociais e a atuação humana no meio ambiente com a identificação de situações que geram problemas ao meio ambiente, a pesquisa aprofundada desta situação, inclusive relacionada às causas e aos agentes causadores do problema, traçar diagnóstivos visando soluções.

A educação ambiental deve estar centrada no estudo de problemáticas ambientais, com seus componentes sociais e biofísicos e suas controvérsias inerentes: 
identificação de uma situação-problema, pesquisa desta situação (inclusive a analise de valores dos protagonistas), diagnósticos, busca de soluções que podem não esta incluída nesta proposição. (SATO, 2005, p. 21).

$\mathrm{Na}$ busca pelo desenvolvimento de habilidades voltadas ao desenvolvimento sustentável é importante que a conscientização se inicie desde a infância expandindo por toda a sociedade. E é com a ampliação da formação ecológica que existirá a possibilidade de um futuro com menor índice de agressões ao meio ambiente, com o uso racional dos recursos naturais, evitando-se a agressão pela ação humana com ações efetivas para reversão do quadro que se encontra.

A educação deve ser o centro dessa mudança, não podendo ficar a margem do problema. E quando tratamos de educação, há sempre a necessidade de se observar todas as situações e, em se tratando de educação ambiental o primeiro passo é a preocupação no desenvolvimento de uma consciência ecológica voltada para a sustentabilidade rumo ao desenvolvimento sustentável.

De acordo com David Hutchison (2000) há o reconhecimento da educação ambiental se dê desde a infância:

Um currículo que vise nutrir nas crianças uma visão ecologicamente sensível do mundo precisa atentar para as qualidades fundamentais dessas e de outras experiências implícitas, dar às crianças experiências de aprendizagem similarmente poderosas, ricamente recompensadoras, ativamente engajadoras, as quais conduzam às tarefas desenvolvimentais da segunda infância. (HUTCHISON, 2000, p. 138)

A escola é um dos principais locais para a atuação de pessoas na mudança de conscientização ambiental onde as atitudes voltadas ao cuidado ecológico e à preservação deve ser estimulada desde os primeiros anos escolares.

Não há como negar que a formação na infância tende-se a ser mais efetiva, pois as crianças ainda não possuem conceitos formados sobre o meio ambiente diferentemente dos adultos que necessitam desconstruir certos conceitos e hábitos para tomar uma postura voltada para uma nova consciência ecológica.

Reconhecidamente é no ambiente escolar que se propagará os valores e atitudes responsáveis, respeitando a diversidade ambiental conscientizando as crianças do uso racional dos recursos naturais de maneira sustentável.

No entanto, a educação ambiental não deve se desenvolver de forma fragmentada e a escola é somente um dos locais onde ela ocorra, mas é necessário que a criança, ao se relacionar em sociedade também consiga detectar atitudes voltadas para a sustentabilidade sob pena de 
não aplicação do conhecimento aprendido.

A escola tem o papel de proporcionar uma conexão entre as várias áreas do conhecimento presentes na sociedade, sendo está conexão imprescindível para que a educação ambiental aconteça. O conhecimento sobre a complexidade e diversidade de questões sobre o meio ambiente possibilita um cuidado melhor com o planeta Terra.

A política também tem um importante papel nessa transformação, pois o tratamento de assuntos relacionados ao meio ambiente é fundamentalmente um problema político. Para que surja uma nova cultura algumas transformações profundas nas relações da sociedade com a natureza são necessárias onde a associação de pessoas, ambiente e política pode propiciar a minimização das catástrofes ambientais.

Para que ocorra a resolução dos crescentes e complexos problemas ambientais é necessário que haja uma mudança radical nos sistemas de comportamentos e valores gerados pela sociedade. De acordo com Jacobi (2003):

\footnotetext{
"Refletir sobre a complexidade ambiental abre uma estimulante oportunidade para compreender a gestação de novos atores sociais que se mobilizam para a apropriação da natureza, para processo educativo articulado e compromissado com a sustentabilidade e a participação, apoiado numa lógica que privilegia o dialogo e a interdependência de diferentes áreas do saber.” (JACOBI, Pedro 2003, p.191)
}

Além do reconhecimento da importância da escola como meio de transformação da consciência ecológica, o educador também necessita de uma mudança de conceitos percebendo que a incorporação da interdisciplinaridade no trabalho do educador deve ser gradativa e a cada dia encontrar possibilidades para a interação do ensino de educação ambiental com outras disciplinas.

Ainda segundo CARVALHO a educação na escola ainda está “organizada sobre a lógica dos saberes disciplinares” tratando questões importantes de uma única perspectiva. Porém, relata ainda que os educadores percebem cada vez mais que certas situações, quando tratadas de modo disciplinar, demonstram espaços que não são possíveis preencher de forma linear. Então "cada dia mais os educadores - principalmente os educadores ambientais - têm sido confrontados com a necessidade de incorporar a dimensão interdisciplinar em suas atividades” CARVALHO (1998, p.8).

Segundo Jacobi (2003), é preciso romper com a cultura dominante: 
concretizará principalmente pela presença crescente de uma pluralidade de atores que, pela ativação do seu potencial de participação, terão cada vez mais condições de intervir consistentemente e sem tutela nos processos decisórios de interesse público, legitimando e consolidando propostas de gestão baseadas na garantia do acesso à informação e na consolidação de canais abertos para a participação, que, por sua vez, são precondições básicas para a institucionalização do controle social.” (JACOBI, Pedro 2003, p.203)

A educação ambiental tem a responsabilidade de demonstrar a necessidade de se repensar práticas sociais reconhecendo o papel dos educadores como incentivadores de pensamentos novos além de serem apenas mediadores e transmissores de um conhecimento necessário fazendo com que os alunos adquiram uma compreensão essencial do meio ambiente global e local, sendo capazes de tomar decisões relacionadas à interdependência dos problemas e soluções conscientizando-se da importância da responsabilidade de cada um para construir uma sociedade mais igualitária e ambientalmente ecologicamente sustentável para a presente e as futuras gerações.

Não pode ser desprezado o conhecimento prévio dos alunos, ao contrário, deve a escola iniciar o tratamento da educação ambiental a partir destes conhecimentos. Permitindo que os alunos possam analisar a meio ambiente e a necessidade de um desenvolvimento de forma sustentável de acordo com as práticas sociais.

O estímulo a uma análise crítica pode contribuir profundamente para as mudanças de valores sobre o cuidado com o meio ambiente fazendo da escola um importante local para a reflexão sobre o meio ambiente e a necessidade de mudança na maneira de utilização dos recursos naturais proporcionando o desenvolvimento sustentável.

A conscientização quanto ao desenvolvimento sustentável é gradativo e começa com pequenas ações onde o ser humano passa a compreender que o uso indevido dos recursos naturais pode afetar sua qualidade de vida e do resto do mundo, inclusive das futuras gerações, e que o cuidado com o meio ambiente não é somente responsabilidade do poder público.

Além disso, o desenvolvimento de forma sustentável somente se dá quando os cidadãos participam ativamente dos processos decisórios assumindo, com isso, sua coresponsabilidade na fiscalização e controle dos agentes responsáveis pela degradação ambiental.

Conforme Márcia N. Silva ${ }^{8}$ já existe um grande avanço no Brasil por meio da Lei

\footnotetext{
${ }^{8}$ SILVA, Márcia N., A educação ambiental na sociedade atual e sua abordagem no ambiente escolar. Disponível em http://www.ambito-juridico.com.br/site/?n_link=revista_artigos_leitura\&artigo_id=11367. Acesso em 23 de Março de 2017.
} 
9.795/99, regulamentada pelo Decreto 4.281/02 visando estimular e regulamentar a Educação Ambiental. Segundo esta Lei, as atividades vinculadas à Política Nacional de Educação Ambiental devem ser desenvolvidas na educação em geral e na educação escolar através: da capacitação de recursos humanos, dos desenvolvimentos de estudos e pesquisas, da produção de material educativo e do acompanhamento e avaliação.

Já com relação à educação formal a lei analisa dois aspectos importantes prevendo que a educação ambiental deve ser desenvolvida em todos os níveis e modalidades do ensino formal e o que a educação ambiental deve ser desenvolvida como prática educativa integrada, contínua e permanente e não deve ser implantada como disciplina isolada de forma específica no currículo escolar.

\section{CONCLUSÃO}

O reconhecimento da necessidade de uma mudança de paradigmas buscando o pleno Desenvolvimento Sustentável traz a consciência de que a Educação Ambiental é indispensável, pois se mostra a maneira mais direta e efetiva de se atingir o conhecimento das práticas visando à sustentabilidade, em que a necessidade do controle ambiental, que apesar de recentes e de não terem sido totalmente incorporadas em nosso meio educacional, mostra-se como um importante mecanismo para a efetivação do direito fundamental ao meio ambiente ecologicamente equilibrado para todos.

Há a necessidade de que seja estimulada uma cultura de consumo e utilização dos recursos naturais buscando uma nova concepção na relação do homem com o meio ambiente. Não adianta apenas a utilização de tecnologias de controle de última geração se as pessoas não repensarem sobre o suas atitudes no que se refere ao consumo e ao uso insustentável dos recursos naturais e o nosso grande desafio é promover o desenvolvimento sustentável de forma eficiente e efetiva.

Novos valores devem ser criados e a educação ambiental deve estar relacionada com um projeto mais amplo de educação para a cidadania que visa à ideia de que o ser humano reveja suas atitudes, pensamentos e comportamento diante a maneira de se consumir, com estimulo a uma reflexão sobre valores individuais, coletivos e transgeracionais.

É importante entender que hoje não podemos mais nos posiciona como mero espectador dos fatos, pois somos todos responsáveis pelo futuro que estamos construindo. A consciência ambiental é importante instrumento, pois somos a primeira geração que dispõe da 
compreensão das mudanças causadas pelo homem no meio ambiente do planeta e da importância de se colocar em prática a educação ambiental como forma de mudar o curso da história ambiental do planeta.

As mudanças climáticas estão mais rápidas e profundas do que se previa até agora. É latente a necessidade da conscientização, pois as mudanças climáticas são um sinal e estão causando um impacto muito maior do que a maioria dos cientistas tinha previsto.

O enfrentamento do aquecimento global é um desafio de grandes proporções e necessita da participação do poder público, da sociedade e da conscientização de que cada um deve fazer sua parte, pois pequenas atitudes é que fazem grandes transformações, a exemplo do que vivenciamos ao longo de nossa história.

Reconhecendo a sustentabilidade como um princípio constitucional, de caráter vinculante, que tem o condão de modificar profundamente o modo de conceber e significar todos os ramos do Direito devemos desfazer as falácias que inibem a eficácia da prevenção, da precaução e da responsabilidade pelo meio ambiente ecologicamente equilibrado defendendo um Estado Sustentável, com políticas de longo prazo voltadas para o bem estar das gerações presente e futuras onde a educação ambiental tem um papel transformador na conscientização ambiental.

\section{REFERÊNCIAS}

ABÍLIO, F. J. P. Ética, cidadania e educação ambiental. In: ANDRADE, M. O. De (Org.). Meio Ambiente e Desenvolvimento: Bases para uma formação multidisciplinar. João Pessoa: Universitária da UFPB, 2008.

BRASIL. Constituição (1988). Constituição da República Federativa do Brasil. Brasília, DF: Senado, 1988.

CARVALHO, Isabel Cristina Moura de. GRÜN, Mauro e TRAJBER, Rachel. Pensar o Ambiente: bases filosóficas para a Educação Ambiental. - Brasília: Ministério da Educação, Secretaria de Educação Continuada, Alfabetização e Diversidade, UNESCO, 2006.

FREITAS, Juarez. Sustentabilidade: Direito ao Futuro. 3a . Edição. Belo Horizonte: Fórum, 2016.

HUTCHISON, David. Educação ecológica: ideias sobre consciência ambiental / David Hutchison; trad. Dayse Batista - Porto Alegre: Artes Médicas Sul, 2.000.

JACOBI, Pedro. Educação Ambiental, Cidadania e Sustentabilidade. Cadernos de Pesquisa, n.118, março/2003. 
ONU. Comissão Mundial sobre Meio Ambiente e Desenvolvimento. Nosso futuro comum. $2^{\mathrm{a}}$ ed. Rio de Janeiro: Editora da Fundação Getúlio Vargas, 1991.

UNESCO. Education for Sustainable Development Goals - Learning Objectives Published in 2017 by the United Nations Educational, Scientific and Cultural Organization, 7, place de Fontenoy, 75352 Paris 07 SP, France.

SILVA, Márcia N., A educação ambiental na sociedade atual e sua abordagem no ambiente escolar. Disponível em http://www.ambito-juridico.com.br/site/?n_link=revista artigos_leitura\&artigo_id=11367. Acesso em 23 de Março de 2017. 